\title{
Carbon Dioxide Fixation by Baker's Yeast in a Variety of Growth Conditions
}

\author{
By ERKKI OURA,* SAMPSA HAARASILTA $\dagger$ \\ AND JOHN LONDESBOROUGH \\ Research Laboratories of the State Alcohol Monopoly (Alko), Box 350, \\ $S F-00101$ Helsinki 10, Finland
}

(Received 16 November 1979)

Fixation of $\mathrm{CO}_{2}$ by Saccharomyces cerevisiae growing under ${ }^{14} \mathrm{CO}_{2}$ in a chemostat was investigated. Under anaerobic conditions, $\mathrm{CO}_{2}$ provided $6.5 \pm 1 \%$ of the total carbon of yeast grown on glucose and $1.6 \%$ of the total carbon of yeast grown on glucose plus excess aspartate. Under aerobic conditions, $2.6 \%$ of the yeast carbon was derived from exogenous $\mathrm{CO}_{2}$ during growth on glucose or glycerol, and $3 \cdot 3 \%$ during growth on pyruvate or ethanol.

The distribution of the fixed carbon among chemical components of the yeast, including some individual amino acids, was determined. Equilibration of $\mathrm{CO}_{2}$ across the cell membrane was probably not quite complete. Under anaerobic conditions, the similar molar radioactivities of aspartate and glutamate indicated that oxaloacetate was not metabolically compartmented. The unequal labelling of aspartate and glutamate during aerobic growth was consistent with operation of the glyoxylate bypass and/or compartmentation of oxaloacetate. Increased $\mathrm{CO}_{2}$ fixation and labelling of carbohydrate during growth on pyruvate or ethanol are ascribed to the activity of phosphoenolpyruvate carboxykinase.

\section{INTRODUCTION}

Rockwell \& Highberger (1927) showed that Saccharomyces cerevisiae requires $\mathrm{CO}_{2}$ in order to grow. Several essential biosynthetic steps are now known that incorporate $\mathrm{CO}_{2}$ (or $\mathrm{HCO}_{3}^{-}$) into cell constituents, such as amino acids and nucleotides, while other reactions, such as the formation of malonyl-CoA via acetyl-CoA carboxylase, involve $\mathrm{CO}_{2}$, although they do not lead to its permanent fixation. However, there are few experimental results on the extent of utilization of $\mathrm{CO}_{2}$ by growing yeast. Apparently, growing $S$. cerevisiae and Candida utilis can obtain $4.8 \%$ and $3.5 \%$, respectively, of their total cell carbon from $\mathrm{CO}_{2}$ (Liener \& Buchanan, 1951). Sorokin (1965) reported a smaller value, $1.8 \%$, for Candida utilis. Oura (1974a) has calculated that, in theory, $6 \cdot 3 \%$ of the carbon of a yeast of average composition is derived from $\mathrm{CO}_{2}$ when all oxaloacetate regeneration proceeds through pyruvate carboxylase, but only $1 \cdot 3 \%$ when the glyoxylate bypass fully replaces the pyruvate carboxylase reaction. The present study is a quantitative investigation of the fixation of $\mathrm{CO}_{2}$ by baker's yeast during growth on different carbon sources under aerohic or anaerobic conditions.

\section{METHODS}

Organism and growth conditions. A baker's yeast, Saccharomyces cerevisiae strain no. 306 from the collection of our laboratories, was used. The yeast was cultivated continuously at a maintained $\mathrm{pH}$ of $4.5,28^{\circ} \mathrm{C}$ and a dilution rate of $0.1 \mathrm{~h}^{-1}$ in a 2.71 Biotec fermenter, type FL103 (LKB, Sweden) with the carbon source as the growth-limiting factor. Except for some special arrangements described below, the

† Present address: SOK Grain Processing Industry, Box 9, SF-37101 Nokia, Finland. 
culture conditions and the composition of the synthetic medium were as described by Oura (1974b). The carbon sources were $5 \%(\mathrm{w} / \mathrm{v})$ glucose, $5 \%$ glucose plus $0.5 \%$ aspartate, $2 \%$ glycerol, $5 \%$ pyruvic acid, or $2.5 \%$ ethanol. To obtain a satisfactory growth rate with glycerol, the medium was supplemented with an ethanolic extract of dried egg yolk (the part of $0.3 \mathrm{~g}$ dried egg yolk extracted with $3 \mathrm{ml}$ hot ethanol was added to $1 \mathrm{l}$ medium: personal communication from Dr C. Gancedo, Madrid, Spain). Pyruvic acid was purified by vacuum distillation and neutralized with $\mathrm{KOH}$. The growth medium was gassed with air (aerobic cultivations) or $\mathrm{O}_{2}$-free $\mathrm{N}_{2}$ (anaerobic cultivations) at $70 \mathrm{l} \mathrm{h}^{-1}$ through a filter. A solution containing $50 \mathrm{~mm}-\mathrm{KHCO}_{3}$ in $1 \mathrm{M}-\mathrm{KOH}$, with or without $12.5 \mathrm{mCi} \mathrm{NaH}^{14} \mathrm{CO}_{3} \mathrm{l}^{-1}$, was continuously added at $7 \mathrm{ml} \mathrm{h}^{-1}$. The culture vessel, medium, pH adjusting solution and an anti-foaming device were sterilized in steam at $120{ }^{\circ} \mathrm{C}$ for $30 \mathrm{~min}$, and the bicarbonate solutions were sterilized using a Millipore filter.

Labelling of yeast with ${ }^{14} \mathrm{CO}_{2}$. When the dry matter content of the outflowing culture became constant, the unlabelled bicarbonate solution was replaced by the labelled solution. Exhaust gas and outflowing medium were led separately into $\mathrm{NaOH}$ solution. Yeast in the fermenter was harvested by centrifugation and washed with water $50 \mathrm{~h}$ after starting the input of ${ }^{14} \mathrm{CO}_{2}$. The spent medium and lyophilized yeast were stored at $-18^{\circ} \mathrm{C}$ until analysed.

Determination of the radioactivities of evolved $\mathrm{CO}_{2}$ and yeast carbon. Several (up to 50) $100 \mathrm{ml}$ samples of exhaust gas were analysed with an Orsat gas analyser. The radioactivity of the $\mathrm{CO}_{2}$ absorbed by the $\mathrm{NaOH}$ solution of the analyser was determined by liquid scintillation, using 50 to $250 \mu 1$ samples, $5 \mathrm{ml}$ methanol and $10 \mathrm{ml}$ Insta-Gel (Packard Instrument Co., Downers Grove, Ill., U.S.A.). An internal standard of $\mathrm{NaH}^{14} \mathrm{CO}_{3}$ was used.

Acid-stable total carbon and ${ }^{14} \mathrm{C}$ contents of the yeast were determined after hydrolysis of samples containing $1 \mathrm{mg}$ dry wt of yeast $\mathrm{ml}^{-1}$ in $3 \mathrm{M}-\mathrm{HCl}$ at $110^{\circ} \mathrm{C}$ for $4 \mathrm{~h}$. Portions of the hydrolysate were analysed for total carbon and nitrogen with a CHN Analyser (Model 1104; Carlo Erba, Milan, Italy) or evaporated to dryness, dissolved in water, and counted by liquid scintillation in the presence or absence of ${ }^{D L}-\left[1-{ }^{14} \mathrm{C}\right]-$ glutamic acid internal standard.

Chemical fractionation of the yeast. Lipids were extracted from $500 \mathrm{mg}$ dry wt of lyophilized yeast with chloroform/methanol $(2: 1, \mathrm{v} / \mathrm{v})$ (Folch et al., 1957) and their radioactivity was determined after evaporation of the solvent. The lipid-free yeast was then hydrolysed and fractionated into a cationic fraction (amino acids, and adenine, guanosine, cytosine and their derivatives), an anionic fraction (uracil, thymine and their derivatives, and non-amino organic acids) and a neutral fraction (mainly carbohydrate). Samples of $25 \mathrm{mg}$ dry wt of lipid-free yeast were hydrolysed in $5 \mathrm{ml} 3 \mathrm{M}-\mathrm{HCl}$ for $5 \mathrm{~h}$ at $110^{\circ} \mathrm{C}$ in a sealed glass tube. The $\mathrm{HCl}$ was then evaporated and a slurry containing $50 \mathrm{ml}$ Dowex $50 \mathrm{~W}-\mathrm{X} 8\left(\mathrm{H}^{+}\right.$form) cation exchange resin in $50 \mathrm{ml}$ water was added, and the $\mathrm{pH}$ was adjusted to about 2 with $\mathrm{HCl}$. Anionic and neutral compounds were removed by four washes with $100 \mathrm{ml}$ water, and cationic compounds were then eluted with three lots of $75 \mathrm{ml} 1 \mathrm{M}$ $\mathrm{NH}_{4} \mathrm{OH}$. Anionic compounds were adsorbed from the water washes by addition of $50 \mathrm{ml}$ Dowex 1-X8 (formate form) anion exchange resin suspended in $50 \mathrm{ml}$ water. The $\mathrm{pH}$ was adjusted to about 10 with $\mathrm{NH}_{4} \mathrm{OH}$. Neutral compounds were removed by four washes with $100 \mathrm{ml}$ water, and anionic compounds then eluted with four lots of $100 \mathrm{ml} 6 \mathrm{M}$-formic acid. The radioactivity of these fractions was determined after concentration and removal of $\mathrm{NH}_{3}$ and formic acid by evaporation.

Determination of the molar radioactivities of amino acids. A portion of the cationic fraction corresponding to about $7.5 \mathrm{mg}$ dry wt of yeast was further hydrolysed in $6 \mathrm{M}-\mathrm{HCl}$ for $24 \mathrm{~h}$ at $110^{\circ} \mathrm{C}$, and then dried in vacuo and dissolved in water. The amino acid composition of one portion was determined with a Beckman Spinco 120B Amino Acid Analyser (Beckman Instruments, Palo Alto, Calif., U.S.A.) (Spackman et al., 1958). A second portion, containing not more than $250 \mathrm{nmol}$ amino acids, was fractionated by high voltage electrophoresis (Ryle et al., 1955): after a first run at $\mathrm{pH} 6.5(5 \mathrm{~min}$ at $1 \mathrm{kV}$, and $45 \mathrm{~min}$ at $3 \mathrm{kV}$ ) on Whatman $3 \mathrm{MM}$ paper, the zone of neutral amino acids was cut off, and sown to a second sheet of paper for electrophoresis at pH 1.9 (40 min at $3 \mathrm{kV}$ ). Amino acid zones, identified by comparison with standard and duplicate samples run in parallel and stained with ninhydrin, were cut out, and the acids were eluted at $\mathrm{pH} 6 \cdot 5$, dried in vacuo, dissolved in water and their radioactivity was determined.

Radioactivity measurements. Unless otherwise stated, samples were suspended in Insta-Gel and counted with a Packard Tri-Carb 2420 liquid scintillation spectrometer.

Other determinations. Carbohydrate (Pfäffli \& Suomalainen, 1960), RNA (Mejbaum, 1939), DNA (Burton, 1956) and lipid (Folch et al., 1957) were determined by standard methods. Total protein was taken to be the difference between the nucleic acids and 6.25 times the total nitrogen. Phosphoenolpyruvate carboxykinase (EC 4.1.1.49), pyruvate carboxylase (EC 6.4.1.1) (Haarasilta \& Oura, 1975), malate dehydrogenase (EC 1.1.1.37) (Ochoa, 1955) and isocitrate lyase (EC 4.1.3.1) (Dixon \& Kornberg, 1959) were determined by the methods indicated in cell-free extracts prepared (Haarasilta \& Oura, 1975) from samples taken on at east two different days from steady-state cultures. The activities of enzymes are expressed per mg protein in the cell-free extracts determined by the Lowry method. 


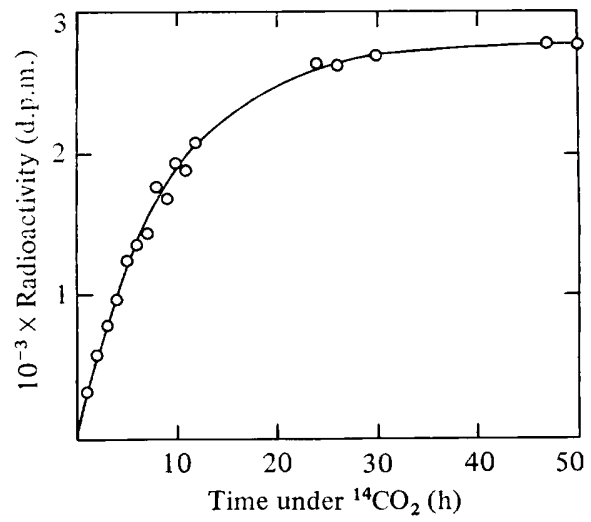

Fig. 1. The acid-stable ${ }^{14} \mathrm{C}$ activity of the culture suspension after exposure to ${ }^{14} \mathrm{CO}_{2}$. Yeast was cultivated aerobically on $5 \%$ glucose, $0.2 \mathrm{ml}$ samples from outflowing culture suspension were added to $5 \mathrm{ml} 3 \mathrm{M}-\mathrm{HCl}$ and hydrolysed in sealed glass tubes at $110^{\circ} \mathrm{C}$ for $4 \mathrm{~h} .{ }^{14} \mathrm{C}$ activity was estimated after dissolving the evaporated samples in water.

Chemicals. DL-[1-14 C]Glutamic acid $\left(29 \mathrm{mCi} \mathrm{mmol}^{-1} ; \quad 1.07 \mathrm{GBq} \mathrm{mmol}^{-1}\right)$ and $\mathrm{NaH}^{14} \mathrm{CO}_{3}\left(59 \mathrm{mCi}^{-1}\right.$ $\mathrm{mmol}^{-1} ; 2 \cdot 18 \mathrm{GBq} \mathrm{mmol}^{-1}$ ) were from The Radiochemical Centre, Amersham. Other reagents were from Boehringer, Fluka, Merck and Sigma.

\section{RESULTS}

The carbon contents of the yeast grown under anaerobic and aerobic conditions with different substrates (see Table 1) were between 44.5 and $45.6 \%$ of their dry weights. Their contents of carbohydrate and protein are given in Table 1 . RNA varied from $7 \cdot 4$ to $9 \cdot 4 \%$ of dry weight, DNA from 0.4 to $0.6 \%$, and lipid from $2 \cdot 5$ to $4.5 \%$.

The acid-stable radioactivity of all the cultures became constant about $30 \mathrm{~h}$ after the start of the labelled bicarbonate feed (e.g. Fig. 1). To ensure that the label was distributed according to steady-state conditions, cultivations were continued for another $20 \mathrm{~h}$ before harvesting the yeast. The amounts of $\mathrm{CO}_{2}$ fixed in the yeast and the distribution of label among various chemical fractions of the yeast are shown in Table 1. The values given are from individual steady-state cultures. The radioactivities of the evolved $\mathrm{CO}_{2}$ and of the yeast [as d.p.m. (mg dry wt $)^{-1}$ ] were reproducible to $\pm 7 \%$. The distribution of label among the chemical fractions of yeast grown aerobically on glucose or ethanol in two pilot experiments (not shown) agreed with the values in Table 1 within $\pm 10 \%$ (i.e. \pm 8 at $80 \%$, and \pm 0.8 at $8 \%$ ). In calculating the amount of yeast carbon derived from $\mathrm{CO}_{2}$, it has been assumed that there is no isotope effect between ${ }^{12} \mathrm{C}$ and ${ }^{14} \mathrm{C}$ (see O'Leary, 1976) and that the molar radioactivity of the cellular $\mathrm{CO}_{2}$ pool available for carboxylation reactions is equal to that of the evolved $\mathrm{CO}_{2}$ in the exhaust gas. This second assumption is discussed later.

Under all growth conditions very little label was incorporated into lipids and only during growth on ethanol and pyruvate was a significant amount of label found in the non-lipid neutral fraction, which presumably consists mainly of carbohydrate. The anionic fraction contained 11 to $19 \%$ of the fixed $\mathrm{CO}_{2}$. The bulk of the fixed radioactivity (70 to $90 \%$ ) was always found in the cationic fraction. On the basis of their $\mathrm{p} K$ values, amino acids and adenine, guanosine, cytosine and their derivatives are expected to be in this fraction. Aspartate and glutamate together accounted for 30 to $50 \%$ of the total radioactivity found in amino acids. The molar radioactivities of six amino acids are shown in Table 2 . The values have been normalized to the same molar radioactivity ( 683 d.p.m. $\mu \mathrm{mol}^{-1}$ ) of evolved $\mathrm{CO}_{2}$ by multiplying the observed radioactivity of the amino acids by 683 divided by the observed molar radioactivity of evolved $\mathrm{CO}_{2}$ from column 4 of Table 1). It is notable that the molar radioactivity of threonine differed from that of its precursor, aspartate, by only 3 to 
ت्.

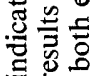

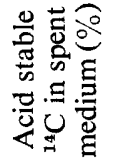

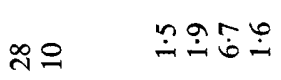

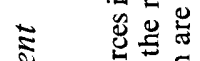

家.

政宽

鞄高垔

过

产要

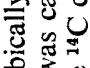

过需

tั

帘员

홍

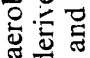

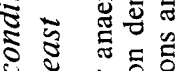

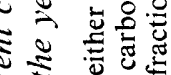

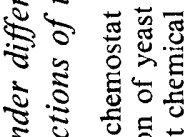

₹

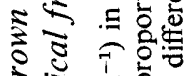

के $\frac{1}{2} \frac{1}{0}$

ธัฐ छ

ح

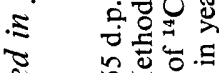

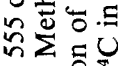

$\ddot{2} \cong$.

○ी

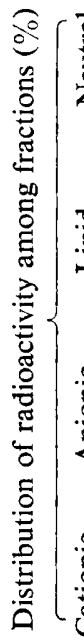

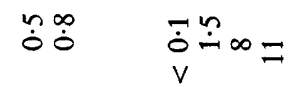

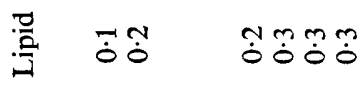

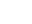

$=2 \quad \pm m \Xi 9$

黄

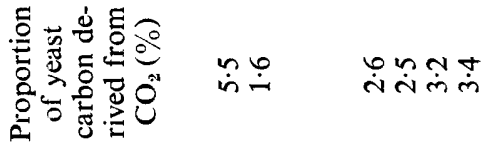

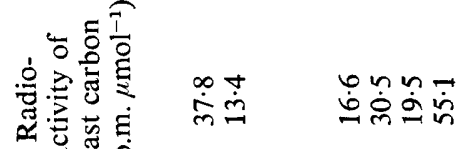

号密要

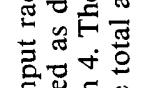

哥芯

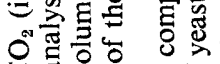

ट्र

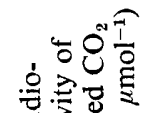

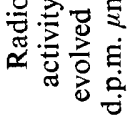

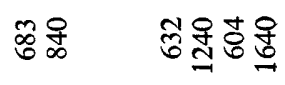

(

₹

․

言兘合学

战导

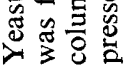

密

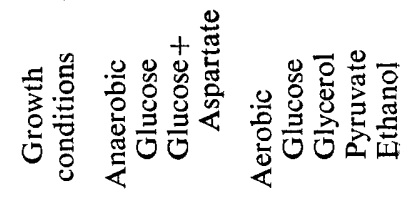


Table 2. Molar radioactivities of six amino acids and activities of four enzymes in yeast grown under different conditions The yeast cultures were the same as in Table 1 . Amino acids and enzymes were isolated and assayed
as described in Methods. The molar radioactivities of the amino acids (d.p.m. $\mu$ mol $\left.^{-1}\right)$ are the results
of single determinations and are normalized to the same molar radioactivity $\left(683\right.$ d.p.m. $\mu \mathrm{mol}^{-1}$ )
of evolved $\mathrm{CO}_{2}$, as described in the text. Enzyme activities [nmol min ${ }^{-1}(\mathrm{mg} \text { protein) })^{-1}$ ] are means
of at least two determinations.

Growth conditions

\begin{tabular}{|c|c|c|c|c|c|c|}
\hline \multirow[b]{3}{*}{ Amino acid } & \multicolumn{2}{|c|}{ Anaerobic } & \multicolumn{4}{|c|}{ Aerobic } \\
\hline & Glucose & $\begin{array}{c}\text { Glucose + } \\
\text { Aspartate }\end{array}$ & Glucose & Glycerol & Pyruvate & Ethanol \\
\hline & & & & & & \\
\hline Aspartate & 498 & 118 & 309 & 244 & 467 & ND \\
\hline Threonine & 482 & 107 & 330 & 218 & 441 & ND \\
\hline Glutamate & 564 & 128 & 195 & 148 & 336 & ND \\
\hline Proline & 523 & 124 & 213 & 127 & 336 & ND \\
\hline Glycine & 24 & 10 & 40 & 52 & 320 & ND \\
\hline Alanine & 24 & 12 & 19 & 31 & 227 & ND \\
\hline \multicolumn{7}{|l|}{ Enzyme } \\
\hline Pyruvate carboxylase & 116 & 19 & 56 & 32 & 33 & 42 \\
\hline Isocitrate lyase & 0.9 & $0 \cdot 3$ & 11 & 86 & 126 & 302 \\
\hline $\begin{array}{l}\text { Phosphoenolpyruvate } \\
\text { carboxykinase }\end{array}$ & $<0 \cdot 1$ & $<0 \cdot 1$ & $0 \cdot 1$ & 0.9 & $4 \cdot 2$ & $7 \cdot 3$ \\
\hline Malate dehydrogenase & 1200 & 1100 & 3300 & 4300 & 5700 & 7100 \\
\hline
\end{tabular}

$12 \%$ over a nearly fivefold range of molar radioactivities. Similarly, the molar radioactivity of proline was always equal to that of its precursor, glutamate. These identities are evidence that the observed labelling patterns reflect steady-state conditions.

The amount of acid-stable radioactivity found in the medium was rather small under aerobic conditions (except after growth on pyruvate) but was $28 \%$ and $10 \%$, respectively, of that found in the cells during anaerobic growth on glucose or glucose plus aspartate. The chemical nature of this extracellular fixed $\mathrm{CO}_{2}$ was not investigated in the present work.

The amounts of pyruvate carboxylase and phosphoenolpyruvate carboxykinase, isocitrate lyase (as a marker for the glyoxylate bypass) and malate dehydrogenase determined by in vitro assays of the yeast samples are shown in Table 2.

\section{DISCUSSION}

The proportion of yeast carbon derived from $\mathrm{CO}_{2}$ was largest during anaerobic growth on glucose alone being then $5.5 \%$ (Table 1). The calculation in Table 1 assumes that the molar radioactivity of the cellular pool of $\mathrm{CO}_{2}$ was the same as that of the $\mathrm{CO}_{2}$ in the exhaust gas, whereas it may have been only $73 \%$ of this, as was that of aspartate (see below). If so, the proportion of yeast carbon derived from $\mathrm{CO}_{2}$ would be higher by a factor of $1 \cdot 35$, i.e. it may be as large as $7 \cdot 4 \%$. Thus, $6.5 \pm 1 \%$ of the yeast carbon was derived from $\mathrm{CO}_{2}$. Liener \& Buchanan (1951) found $4.8 \%$ during batch growth of $S$. cerevisiae. Oura (1974a) obtained a theoretical value of $6.3 \%$ for a model yeast containing a similar proportion of protein $(39 \%$ ) to the present yeast (about $42 \%$ ).

The smallest proportion of yeast carbon derived from $\mathrm{CO}_{2}$ was $1.6 \%$, during anaerobic growth on glucose plus aspartate (Table 1). This is not much more than the theoretical value of $1.3 \%$ for growth in the absence of oxaloacetate synthesis via pyruvate carboxylase (Oura, 1974a). The amount of pyruvate carboxylase in this yeast was less than under any other condition (Table 2). However, the molar radioactivity of aspartate was still $17 \%$ of 
that of the evolved $\mathrm{CO}_{2}$ so that aspartate continued to be synthesized via pyruvate carboxylase even when excess aspartate was available (the steady-state concentration of aspartate in the medium was $0.2 \%$ ).

During aerobic growth on glucose both $\mathrm{CO}_{2}$ fixation and pyruvate carboxylase activity were about half the values obtained during anaerobic growth (Tables 1 and 2). The aerobic yeast contained isocitrate lyase (Table 2 ) so that the glyoxylate bypass could lessen the need for oxaloacetate formation via pyruvate carboxylase. The proportion of yeast carbon derived from $\mathrm{CO}_{2}$ during growth on glycerol was similar to that during aerobic growth on glucose. Yeast grown on pyruvate or ethanol contained larger amounts of radioactivity including considerable amounts in carbohydrate. Both observations probably reflect the appearance of phosphoenolpyruvate carboxykinase in these yeasts (see below). The $\mathrm{CO}_{2}$ requirement for purine and pyrimidine synthesis accounts for only a small amount (about $0.8 \%$ of the total yeast carbon; E. Oura, unpublished results) of $\mathrm{CO}_{2}$ fixation, so that the variation in RNA plus DNA content of the different yeasts does not cause a significant variation in $\mathrm{CO}_{2}$ fixation. However, the decreased proportion of carbohydrate and increased proportion of protein is partly responsible for the relatively high proportion of yeast carbon derived from $\mathrm{CO}_{2}$ during growth on pyruvate and ethanol compared with aerobic growth on glucose and glycerol.

Pathways of $\mathrm{CO}_{2}$ fixation during anaerobic growth. The distribution of label from ${ }^{14} \mathrm{CO}_{2}$ among the amino acids from yeast grown in steady-state conditions throws some light on the actual metabolic pathways operating in vivo. Pyruvate carboxylase introduces labelled carbon from ${ }^{14} \mathrm{CO}_{2}$ into the C-4 position of oxaloacetate. This label is transferred by citrate synthase, aconitase and isocitrate dehydrogenase to the $\mathrm{C}-1$ position of 2-oxoglutarate (and glutamate). If the complete tricarboxylic acid cycle is functioning, the label will then be lost during decarboxylation of 2-oxoglutarate, so that unlabelled oxaloacetate will be formed and will dilute the radioactivity of the oxaloacetate pool, unless there are separate metabolic pools of this compound. During anaerobic growth on glucose alone, the molar radioactivity of aspartate, and therefore of its precursor, oxaloacetate, was $73 \%$ of the molar radioactivity of $\mathrm{CO}_{2}$ in the exhaust gas (Table 1). The tricarboxylic acid cycle functions only slowly, if at all, under these conditions, because succinate dehydrogenase and 2-oxoglutarate dehydrogenase are virtually absent (Chapman \& Bartley, 1968; Machado et al., 1975). It follows that the molar radioactivity of the $\mathrm{CO}_{2}$ pool available to pyruvate carboxylase was probably only $73 \%$ of that of the evolved $\mathrm{CO}_{2}$, so that equilibration of $\mathrm{CO}_{2}$ across the cell membrane only reached $73 \%$. This is perhaps not surprising, since the amount of unlabelled $\mathrm{CO}_{2}$ produced inside the cells was 900 -fold greater than the supply of ${ }^{14} \mathrm{CO}_{2}$.

The molar radioactivities of the glutamate and aspartate families of amino acids were close during anaerobic growth on glucose, and both fell by $80 \%$ when exogenous aspartate was supplied. Under these conditions, the oxaloacetate available for glutamate synthesis via citrate synthase must, therefore, be the same oxaloacetate available to pyruvate carboxylase and transaminase, which are both cytosolic enzymes in yeast (Haarasilta \& Taskinen, 1977, and unpublished results). Furthermore, the activity of transaminase is evidently sufficient to equilibrate the carbon skeletons of aspartate and oxaloacetate. The location of citrate synthase in anaerobic yeast is not certain but under some conditions it may be partly in the cytosol (cf. Duntze et al., 1969).

In contrast, interconversion of oxaloacetate and fumarate, leading to partial randomization of the label between C-4 and C-1 of oxaloacetate (cf. Heath, 1968), appears to be very slow in these yeasts, although substantial amounts of malate dehydrogenase were present (Table 2; fumarase levels were not determined). Since both C-4 and C-1 of oxaloacetate are transferred to aspartate, but only $\mathrm{C}-4$ is transferred to glutamate (C-1 is lost in the decarboxylation catalysed by isocitrate dehydrogenase), partial randomization of $\mathrm{C}-4$ and C-1 of oxaloacetate would lead to the molar radioactivity of glutamate being less than that of aspartate. In fact, the molar radioactivities of both proline and its precursor, glutamate, 
were consistently about $10 \%$ greater than those of threonine and its precursor, aspartate. We have no satisfactory explanation for this observation. Exchange between $\mathrm{CO}_{2}$ and 2-oxoglutarate is catalysed very slowly by bacterial 2-oxoacid dehydrogenase complexes (Strecker \& Ochoa, 1954), and aspartase, which might form unlabelled aspartate from fumarate, has not been demonstrated in yeast.

Pathways of $\mathrm{CO}_{2}$ fixation during aerobic growth. The distribution of label during aerobic growth differed from that during anaerobic growth in two important respects. Firstly, the molar radioactivity of glutamate was now much less than that of aspartate (Table 2). This could result either from partial randomization of C-4 and C-1 of oxaloacetate, via fumarase (see above), or via the glyoxylate bypass (which transfers C-4 of oxaloacetate sequentially to the $\mathrm{C}-1$ atoms of glyoxylate, malate and oxaloacetate), or by metabolic compartmentation of oxaloacetate. The relative importance of these three mechanisms cannot be determined by the present results alone: other kinds of information, such as the distribution of label between C-4 and C- 1 of aspartate, are also required. Secondly, significant amounts of label now appeared in carbohydrate. The labelling of carbohydrate ('neutral fraction', Table 1) correlated closely with phosphoenolpyruvate carboxykinase activity (Table 2), as expected, since this enzyme is believed to be the main gluconeogenic route from compounds such as pyruvate and ethanol. The $\mathrm{C}-4$ of oxaloacetate is lost during decarboxylation to phosphoenolpyruvate, so that incorporation of label from ${ }^{14} \mathrm{CO}_{2}$ into carbohydrate by this route requires partial randomization of $\mathrm{C}-4$ and $\mathrm{C}-1$ of oxaloacetate by one of the mechanisms mentioned above.

The large molar radioactivities of glycine (derived from phosphoenolpyruvate) and alanine (derived directly from pyruvate) during growth on pyruvate are remarkable. They probably result from the $\mathrm{CO}_{2}$ /oxaloacetate and pyruvate/oxaloacetate exchanges, catalysed, respectively, by phosphoenolpyruvate carboxykinase (Cannata \& Stoppani, 1963) and pyruvate carboxylase (Gailiusis et al., 1964), becoming rapid compared with the turnover of pyruvate under these conditions (cf. Cazzulo et al., 1968). These exchange reactions probably also contribute to the labelling of carbohydrates in yeast grown on ethanol and pyruvate.

We thank Dr N. Ellfolk, Department of Biochemistry, Helsinki University, for providing advice and facilities for the separation and analysis of amino acids, and Riitta Vainikainen for her skilful technical assistance.

\section{REFERENCES}

Burton, K. (1956). Study of the conditions and mechanism of the diphenylamine reaction for the colorimetric estimation of deoxyribonucleic acid. Biochemical Journal 62, 315-323.

Cannata, J. J. B. \& Stoppani, A. O. M. (1963). Phosphopyruvate carboxylase from baker's yeast. Isolation, purification, and characterization. Journal of Biological Chemistry 238, 1196-1207.

Cazzulo, J. J., Claisse, L. M. \& Stoppani, A. O. M. (1968). Carboxylase levels and carbon dioxide fixation in baker's yeast. Journal of Bacteriology 96, 623-628.

Chapman, C. \& Bartley, W. (1968). The kinetics of enzyme changes in yeast under conditions that cause the loss of mitochondria. Biochemical Journal 107, 455-465.

Dixon, G. H. \& KornberG, H. L. (1959). Assay methods for key enzymes of the glyoxylate cycle. Biochemical Journal 72, 3 P.

Duntze, W., NeumanN, D., Gancedo, J. M., Atzpodien, W. \& Holzer, H. (1969). Studies on the regulation and localization of the glyoxylate cycle enzymes in Sacharomyces cerevisiae. European Journal of Biochemistry 10, 83-89.

Folch, J., Lees, M. \& Sloane-Stanley, G. H. (1957). A simple method for the isolation and purification of total lipids from animal tissues. Journal of Biological Chemistry 226, 497-509.

Gailiusis, J., Rinne, R. W. \& Benedict, C. R. (1964). Pyruvate-oxaloacetate exchange reaction in baker's yeast. Biochimica et biophysica acta 92, 595-601.

HaARasilta, S. \& OURA, E. (1975). On the activity and regulation of anaplerotic and gluconeogenetic enzymes during the growth process of baker's yeast. European Journal of Biochemistry 52, 1-7.

HaARASIlta, S. \& TASkinen, L. (1977). Location of three key enzymes of gluconeogenesis in baker's yeast. Archives of Microbiology 113, 159-161.

HeATH, D. F. (1968). The redistribution of carbon label by the reactions involved in glycolysis, gluconeogenesis and the tricarboxylic acid cycle in rat liver. Biochemical Journal 110, 313-335.

LIENER, I. E. \& BuCHANAN, D. L. (1951). The fixa- 
tion of carbon dioxide by growing and nongrowing yeast. Journal of Bacteriology 61, 527534.

Machado, A., Nuñez de Castro, I. \& Mayor, F. (1975). Isocitrate dehydrogenase and oxoglutarate dehydrogenase activities of baker's yeast grown in a variety of hypoxic conditions. Molecular and Cellular Biochemistry 6, 93-100.

MejBaum, W. (1939). Ưber die Bestimmung kleiner Pentosemengen, insbesondere in Derivaten der Adenylsäure. Hoppe-Seyler's Zeitschrift für physiologische Chemie 258, 117-120.

OCHOA, S. (1955). Malic dehydrogenase from pig heart. Methods in Enzymology 1, 735-739.

O'Leary, M. H. (1976). Carbon isotope effect on the enzymatic decarboxylation of pyruvic acid. Biochemical and Biophysical Research Communications 73, 614-618.

Oura, E. (1974a). Carbon dioxide fixation process in yeast, particularly baker's yeast; theoretical background. Statement presented at the panel discussion, Production of yeast protein from different carbon sources, convenership H. W. D. Katinger, pp. 53-60. In Proceedings of the 4th International Symposium on Yeasts, Vienna, part II, pp. 58-59. Edited by H. Klaushofer \& U. B. Sleytr. Vienna.
OURA, E. (1974b). Effect of aeration intensity on the biochemical composition of baker's yeast. I. Factors affecting the type of metabolism. Biotechnology and Bioengineering 16, 1197-1212.

Pfäffli, S. \& Suomalainen, H. (1960). Determination of the carbohydrate fraction in baker's yeast. Suomen Kemistilehti 33B, 61-65.

Rockwell, G. E. \& Highberger, J. H. (1927). The necessity of carbon dioxide for the growth of bacteria, yeasts and mold. Journal of Infectious Diseases 40, 438-446.

Ryle, A. P., Sanger, F., Smith, L. F. \& Kitai, R. (1955). The disulphide bonds of insulin. Biochemical Journal 60, 541-556.

Sorokin, J. I. (1965). On the trophic role of chemosynthesis and bacterial biosynthesis in water bodies. Memorie dell'Istituto italiano di idrobiologia Dott. Marco de Marchi. Pallanza de Verbania (Suppl. 18), 169-205.

Spackman, D. H., Stein, W. H. \& Moore, S. (1958). Automatic recording apparatus for use in the chromatography of amino acids. Analytical Chemistry 30, 1190-1206.

Strecker, H. J. \& OChOA, S. (1954). Pyruvate oxidation system and acetoin formation. Journal of Biological Chemistry 209, 313-326. 